\title{
Online Journal of Health Ethics
}

\section{The Relationship of Moral Distress, Ethical Environment and Nurse Job Satisfaction}

Francine M. Parker EdD, MSN, RN

Auburn University, parkefm@auburn.edu

Ramona B. Lazenby MSN, RN, CRNP

Auburn University Montgomery, rlazenby@aum.edu

Jennifer L. Brown B.S.Ed., M.Ed., Ed.S, Ph.D.

Columbus State University, brown_jennifer2@columbusstate.edu

Follow this and additional works at: http://aquila.usm.edu/ojhe

Part of the Nursing Commons

\section{Recommended Citation}

Parker, F. M., Lazenby, R. B., \& Brown, J. L. (2013). The Relationship of Moral Distress, Ethical Environment and Nurse Job Satisfaction. Online Journal of Health Ethics, 10(1). http:/ / dx.doi.org/ 10.18785/ojhe.1001.02 
MORAL DISTRESS

THE RELATIONSHIP OF MORAL DISTRESS, ETHICAL ENVIRONMENT AND NURSE JOB SATISFACTION

FRANCINE M. PARKER, EdD, MSN, RN AUBURN UNIVERSITY

RAMONA B. LAZENBY, MSN,RN, CRNP AUBURN UNIVERSITY

JENNIFER L. BROWN, B.S.Ed, M.Ed,EdS, PhD. COLUMBUS STATE UNIVERSITY 


\section{Introduction}

The demand for nurses is likely to intensify in the wake of the restructuring of our health care system with a concurrent need for primary care services, particularly as baby boomers age. The 'United States Registered Nurse Workforce Report Card and Shortage Forecast” put forth that this shortage is likely to spread nationwide between 2009 and 2030, being most intense in the South and West. While the nurse population is expected to grow six percent between the years $2000-2020$, the demand for nurses in the US is expected to grow by forty percent during the same time period (HRSA, 2006). Further, Buerhaus (2009) quantified the projected need for registered nurses as 260,000 by 2025.

Historically, the nursing workforce has managed high turnover rates, increased acuity levels, and evolving staffing patterns reflective of managed care initiatives. However, the current shortage of qualified nurses presents a critical challenge to health care administrators within and beyond the borders of the United States (US), who must recruit, and equally important, retain a stable workforce to meet the current demand as well as prepare for the foreseeable future. Among the many considerations for securing and maintaining a stable nurse workforce include fostering an ethical work environment which could promote job satisfaction and diminish moral distress, with a concomitant improved patient care delivery and satisfaction (Takase et al., 2001). Nurses are routinely challenged to reconcile the dichotomy between professional ethical practice set forth by the International Council of Nurses (2012) and the American Nurses Association Code of Ethics and organizational constraints which often hinder the nurses' ability to address the myriad of challenging dilemmas in the work place. Corley, Elswick, Gorman, and Clor (2001) conducted research in an effort to improve the understanding of moral distress and the possible consequences associated with it. The research was based on the assumptions that nurses carry their values to work, they can 
recognize ethical problems in their job and they can identify the extent to which these problems result in moral distress. Findings from this study indicated that the Moral Distress Scale was valid and reliable. One tenet of the International Council of Nurses Code of Ethics for Nurses (2012) is promoting an environment that is respectful of individuals, families and communities. Further, the nurse is responsible for self-care in order to be able to provide appropriate care. It is also the responsibility of the nurse to promote "ethical behavior and open dialogue" and create a positive and safe working environment.

The Robert Woods Foundation and Institute for Healthcare Improvement initiative, recognizing the high nurse turnover rate in medical surgical nursing units and driven to improve quality care and patient safety began the Transforming Care at the Bedside (Nielsen, et. al., 2008) initiative calling for, among other things, improved work environments. Nurses must be provided an environment where ethical dilemmas, professional relationship issues, and the myriad of workforce challenges inherent within a healthcare environment, can be acknowledged and addressed with resolve.

In this descriptive correlational study, the research team assumed there was a significant correlation between practicing in an ethical environment, nurse moral distress and job satisfaction levels, a relationship established in the literature (Begat, Ellesfsen, \& Severinsson, 2005; Haggstrom, Mbusa, \& Wadensten, 2008; Hamric \& Blackhall, 2007). The current study examined the relationship between nurse moral distress intensity, moral distress frequency and the ethical climate among 61 registered nurses employed full time in two central Alabama hospitals. In addition, the relationship of demographic characteristics to moral distress intensity and frequency were examined. The purpose of this study was to determine the relationship between ethical work environment and moral distress frequency, the relationship between ethical work environment and moral distress intensity, and the relationship between ethical work environment and overall job satisfaction. 


\section{Review of Literature}

\section{Moral Distress}

The classical work by Jameton (1984) proposed a definition of moral distress as "occurring when one knows the right thing to do, but institutional constraints make it nearly impossible to pursue the right course of action" (p. 6). Pendry (2008) expanded the definition to capture physical or emotional suffering which occurs as a result of one not being able to take what is considered the right course of action. Alleviating suffering and improving the patient condition is a fundamental, persistent role of the nurse who practices and delivers patient centered care. As far back as 1998, research has indicated that registered nurses have been concerned about the inability to discuss their clinical care and ethical concerns, lack of support from administrators about ethical clinical care and the inability to have policies and procedures that sustain the ethical care of patients (McDaniel, 1998). Thus, when the nurse is consistently unable to satisfactorily resolve issues, painful emotional and mental anguish associated with moral distress, is likely to ensue. Haggstrom, Mbusa, and Wadensten (2008) vividly illustrated moral distress in nurses' comments indicating feelings of 'discomfort and disinclination' in not being able or equipped to deliver the level of quality care their patients needed or deserved. Further, when the nurse did not perceive being acknowledged or appreciated for attempting to change inadequate care situations, feelings of being overwhelmed or demoralized were commonly expressed.

The causes of moral distress among nurses have been linked to workforce issues, including nurse-to-patient ratios and work environment concerns (Bowles \& Candela, 2005; 
Pendry, 2007). Perhaps the nurses' perception of the organization environment plays a greater role in moral distress than the individual characteristics of the nurse, however, both must be considered as contributors to moral distress. Research conducted by Pauly, Varcoe, Storch, and Newton (2009) supported the notion that there was a significant correlation between levels of moral distress and ethical climate. They further proposed that moral distress may also be the result of nurses failing to pursue what they believe to be the right action. Findings from a Swedish descriptive, cross-sectional comparative and correlational study conducted by Silen et al. (2011) revealed situations that solicited high levels of moral distress included lack of resources, working with people of low competence, and implementing unnecessary treatments. Further findings indicated that nurses had considered leaving the unit due to moral distress.

In a literature review by Schluter et al. (2008), contributing causes of moral distress were categorized as poor quality, futile care, and unrealistic hope. Poor quality and futile care related to work force issues such as understaffing. Nurses may experience moral distress when unrealistic hope is provided by the medical staff to patients. Incomplete or inaccurate information regarding realistic patient outcomes contributes significantly to unrealistic hope (Gallagher, 2011). Schluter et al. (2008) reported that moral distress was noted to negatively impact job satisfaction, and resulted in nurses leaving their positions and/or profession. Further, nurses who experience distress have reported physical and psychological symptoms including gastrointestinal problems, anger, frustration and guilt. In a study of over 1000 nurses and social workers in four U.S. regions, Ulrich et al. (2007) sought to measure their professional job satisfaction, with subscales of global job satisfaction, career satisfaction and specialty satisfaction. Olson's Hospital Ethical Climate Scale (1998) was adapted to measure organizational practice influence on nurses' and social worker engagement in ethical practice, reflection and their perceived ability to resolve issues of an ethical nature. The data support the relationship of a positive ethical environment in improving job satisfaction and addressing ethical 
MORAL DISTRESS

stress. Fatigue, feelings of powerless, frustration, and anger were expressed by a majority of the participants when organizational support was lacking for their dealing with ethical issues.

\section{Ethical Environment}

According to Murray (2007), an ethical environment is one in which the nurse is comfortable raising ethical concerns, is aware of an ethical culture and engages in ethical discussions. In an ethical work environment, also referred to as a healthy work environment, nurses are respected, valued and have a voice regarding issues of concern (Schluter et al., 2008; Sherman \& Pross, 2010). A healthy work environment, described as a place where professionals can have open and positive dialogue with congruence between professional and ethical expectations, serves to improve recruitment, retention and improved patient care. An ethical environment perceived as safe for the nurse to engage in moral decision making is critical for the nurse to feel empowered as a true member of the health care team while serving as a patient advocate.

\section{Research Questions}

1. What is the relationship between ethical climate and frequency of moral distress?

2. What is the relationship between ethical climate and intensity of moral distress?

3. What is the relationship between ethical climate and overall job satisfaction? 


\section{Methodology}

\section{Participants}

The participants included 58 (93.5\%) females and $3(4.8 \%)$ males, and 1 participant did not indicate a gender. In terms of race, $91.9 \%(n=57)$ of the participants were Caucasian and 8.1\% $(n=5)$ were African-American. The sample demographics mirrored the registered nurse population of each of the hospitals. Incidentally, the nurse-patient ratio was similar among nursing both units at both hospitals being 1 nurse to 5 to 6 patients generally. The age ranged from 20 years to greater than 60 years (see Table 1.). The majority of the participants held at least an associate degree or baccalaureate in nursing (see Table 1). Experience as a nurse and experience at this hospital ranged from less than 1 year to more than 10 years. The majority of the participants had nursing experience of more than 10 years (see Table 2).

\section{Data Collection}

The Office of Human Subject Research at Auburn University, Auburn University Montgomery, and the two participating hospitals approved the study. One hospital was a 314 bed regional referral not-for-profit facility. The second study location was a 454 bed faith-based not-for-profit medical center. The hospitals were located 60 miles apart. A cover letter informed potential participants of the nature and purpose of the study and assurance was provided that individual responses would be confidential with only aggregated data reported. An instructional letter was sent to registered nurses at two hospitals within the southeastern United States via email. After the nurse read the information letter and agreed to participate in the study by selecting the survey link, two surveys were combined and administered via Survey Monkey, a web-based survey platform. The first survey was the Moral Distress Scale (MDS), which measured two aspects of moral distress: frequency and intensity (Appendix A). The Hospital 
MORAL DISTRESS

Ethical Climate Survey, the second survey, measured workplace influences on the nurses' ability to practice and make decisions from an ethical perspective (Appendix B). Appendix C reflects demographic data collected.

\section{Measures}

Moral Distress Scale. The 21-item measure was a shortened version of the original 38item Moral Distress Scale (Corley, Elswick, Gorman, \& Clor, 2001), which was devised by Ann Hamric at the University of Virginia School of Nursing. In addition, the seven-point Likert-type was reduced to a five-point Likert-type scale. The participants rate the same situation using a frequency response scale and a level of distress response scale. Participants rated the frequency of the given the situation on a scale ranging from 0 (Never) to 4 (Very Frequently) and rated the level of distress for the given situation on a scale ranging from 0 (None) to 4 (Great Extent). In a pilot study conducted by Hamric and Blackhall (2007) with 196 registered nurses, the Cronbach's alpha reliability coefficient was .85 using the product scores. The Cronbach's alpha coefficient for the frequency scale was .80 using the total scores, and Cronbach's alpha coefficient for the level of distress scale was .79 using the total scores. With Cronbach's alpha of .60 or greater as a criterion (Hair, Black, Babin, Anderson, \& Tatham, 2006), these results suggest that the scales within the survey are internally consistent measures.

Hospital Ethical Climate Survey. The 26-item measure assessed how nurses perceive the ethical climate within their hospital workplace. Participants rated each practice on a scale ranging from 1 (Almost Never True) to 5 (Almost Always True). This measure contained eight items to capture the background information, which included gender, race, birth year, basic nursing education, highest degree earned, years of experience as a registered nurse, years of employment at current hospital, and current nursing position. The demographics 
MORAL DISTRESS

section also asked the participants to rate their level of overall job satisfaction on a scale of 1 to 6 , with 1 being extremely dissatisfied and 7 being extremely satisfied. The measure's construct validity and reliability were evaluated in pilot study by Olson (1998) with 360 registered nurses. The measure was found to have construct validity, and the Cronbach's alpha reliability coefficient was .91. The Cronbach's alpha coefficient was .91. With Cronbach's alpha of .60 or greater as a criterion (Hair et al., 2006), this result suggests that the measure is internally consistent.

\section{Results}

\section{Descriptives}

The total frequency score of Moral Distress ranged from 0 to 34 with a mean of 16.32 and a standard deviation of 8.74. The total intensity score for the level of distress had a mean of 19.84 with a standard deviation of 10.98 . It ranged from 0 to 42 . Both sets of descriptives reveal that there exists some level of distress in the workplace for these registered nurse participants. For ethical climate, the mean scale score ranged from 2.58 to 4.92 . It had a mean of 3.73 with a standard deviation of 0.52 , which indicates many of the practices listed on the survey occurred in the workplace according to these participants.

\section{Research Questions}

Research Question 1. A Pearson Product Moment Correlation was conducted to determine the relationship between ethical climate and frequency of moral distress. There was a weak to moderate relationship $(r=-.255 ; p=.046)$, but there was a negative relationship. Thus, as ethical climate increased, the frequency of moral distress decreased.

Research Question 2. A Pearson Product Moment Correlation was conducted to determine the relationship between ethical climate and intensity of moral distress. There was a 
MORAL DISTRESS

weak, negative relationship $(r=-.119 ; p=.356)$. As ethical climate decreased, the intensity of moral distress increased.

Research Question 3. A Pearson Product Moment Correlation was conducted to determine the relationship between ethical climate and overall job satisfaction. There was a moderate relationship $(r=.388 ; p=.002)$. As overall job satisfaction increased, the ethical climate also increased. Overall job satisfaction ranged from 2 (very dissatisfied) to 6 (extremely satisfied). The mean was 4.31 with a standard deviation of 0.69 , which means the majority of the participants tended to be satisfied with their current job.

\section{Discussion and Implications}

Nursing can be a stressful career choice given the complexity of the health care environment, acuity of patients and explosion of new technology and an increasing demand for accountability in meeting patient safety and quality needs. In order to provide support for nurses in dealing with work related stressors and accompanying moral distress, many programs and initiatives have been put in place. For example, the American Association of Critical Care Nurses (AACN) provides a toolkit, the 4 A's to Rise Above Moral Distress Facilitator Toolkit, to assist nurses in addressing and preventing moral distress (2006). Simulation for the interprofessional team is a strategy whereby complex ethical scenarios can be addressed applying the AACN framework. Strategies to enhance ethical environment "could be related to improving relationships with peers, managers, hospital, patients and physicians as part of recruitment and retention strategies" (Pauley et al., 2009, p. 570). Kupperschmidt, Kientz, Ward, and Reinholz (2010) espouse that a healthy work environment must begin with each nurse being intentional and reflective about their experiences. Using Parse's theory of human becoming (Parse, 1992), which includes becoming aware of self-deception, becoming authentic, becoming candid, becoming mindful, and becoming reflective, nurses can become skilled 


\section{MORAL DISTRESS}

communicators which can ultimately result in a healthier work environment. Other strategies may include a participative leadership model, support groups, mentoring and creation of scared space for nurses to reflect and share thoughts on difficult or challenging concerns (Edmonson, 2010; Mohr \& Horton-Deutsch, 2001; Pijl-Zieber et al., 2008; Repenshek, 2009).

When nurses feel supported within a safe, ethical environment in which their clinical reasoning and judgment are valued, moral distress decreases and job satisfaction increases. According to Haddad (1998), nurses who were involved in ethical discussions perceived a more positive work site. Nursing representation on ethical boards and facilitating ethical roundtable discussions could increase an ethical work environment. Greater decision making ability related to patient care and workforce issues could increase a feeling of empowerment which in turn can positively influence nurse job satisfaction. Storch, Rodney, Pauly, Brown and Starzomski (2002) participated in a practice-based project regarding nurses and nursing student perception of ethical practice and moral distress. Clearly, the nurses' ability to practice ethically was intimately related to organizational climate, availability of necessary resources and the capability or willingness of leadership to address ethical concerns.

According to Kupperschmidt and colleagues (2010), nurses must take responsibility for creating a healthy work environment. This responsibility translates to an atmosphere of openness, positivity and consistency with professional and ethical mandates. As the most trusted profession, managers must seek ways to make certain that nurses are functioning in an ethical environment. Strategies that may be helpful in creating this ethical work environment include first and foremost establishing a trusting environment in which nurses feel safe discussing ethical concerns. Managers then must acknowledge these concerns and seek appropriate resolution.

\section{Limitations and Recommendations for Further Research}


MORAL DISTRESS

There are a few limitations to this study. First, the sample size was small with 62 participants. In addition, the majority of the participants had more than 10 years of total nursing experience, and they had completed most, if not all, of their years of nursing experience at the same facility. Future research could expand the pool of participants, including other hospitals and nurses with varying experience backgrounds. In addition, the specific work unit should be requested on the demographic tool. Due to the small homogenous participant sample, future research could be conducted among a diverse, multicultural workforce.

Another limitation of the study was the variable, job satisfaction, which was measured as a single survey item. In future research, multiple components of job satisfaction could be measured. Additional research possibilities include focus groups of nurses to qualitatively examine ethical climate and overall job satisfaction. Targeting specific work units to identify factors unique to specialty units, as opposed to general medical surgical units, may offer insight regarding specific work environment factors. Research on the number of nurses who actually leave the profession as a result of unresolved ethical dilemmas or moral distress related to job satisfaction need to be conducted. Further research is warranted to determine if moral distress is a factor in a nurse's decision to leave a unit, the organization or ultimately the nursing profession. Finally, future research should include the participant's specific work unit on the demographic data tool. 
MORAL DISTRESS

Table 1

Frequencies and Percentages for Participants' Age Range and Highest Degree Earned

$n \quad \%$

\begin{tabular}{|c|c|c|}
\hline Age Range & & \\
\hline $20-30$ & 9 & 14.5 \\
\hline $31-40$ & 17 & 27.4 \\
\hline $41-50$ & 17 & 27.4 \\
\hline $51-60$ & 17 & 27.4 \\
\hline Greater than 60 & 2 & 3.2 \\
\hline Highest Degree Earned & & \\
\hline Diploma & 4 & 6.5 \\
\hline Associate Degree & 23 & 37.1 \\
\hline Baccalaureate (Nursing) & 22 & 35.5 \\
\hline Baccalaureate (Other Field) & 4 & 6.5 \\
\hline Master's (Nursing) & 7 & 11.3 \\
\hline Master's (Other Field) & 2 & 3.2 \\
\hline Total & 62 & 100 \\
\hline
\end{tabular}

Table 2 


\section{MORAL DISTRESS}

Frequencies and Percentages for Years of Nursing Experience

\begin{tabular}{ccc}
\hline & $n$ & $\%$ \\
\hline $\begin{array}{c}\text { Total Experience } \\
\text { Less than } 1 \text { year }\end{array}$ & 1 & 1.6 \\
1 to 5 years & 11 & 17.7 \\
6 to 10 years & 8 & 12.9 \\
More than 10 years & 38 & 61.3 \\
Missing & 4 & 6.5 \\
\hline Experience at this Hospital & 5 & 8.1 \\
Less than 1 year & 15 & 24.2 \\
1 to 5 years & 11 & 17.7 \\
6 to 10 years & 31 & 50.0 \\
\hline More than 10 years & 62 & 100 \\
\hline Total & &
\end{tabular}




\section{Appendix A}

\section{Moral Distress Scale}

The following situations occur in clinical practice. If you have experienced these situations they may or may not have been disturbing to you. Please indicate how frequently you experienced each item described and how disturbing the experience was for you. If you have never experienced a particular situation, select " 0 " (never) for frequency. Even if you have not experienced a situation, please indicate how disturbed you would be if it occurred in your practice. Note that you will respond to each item by checking the appropriate column for two dimensions: Frequency and Level of

\section{Disturbance.}

\begin{tabular}{|c|c|c|c|c|c|c|c|c|c|c|}
\hline & \multicolumn{5}{|c|}{ Frequency } & \multicolumn{5}{|c|}{ Level of Disturbance } \\
\hline & \multicolumn{2}{|c|}{ Never } & \multicolumn{3}{|c|}{$\begin{array}{l}\text { Very } \\
\text { frequently }\end{array}$} & \multicolumn{2}{|c|}{ None } & \multicolumn{3}{|c|}{$\begin{array}{l}\text { Great } \\
\text { extent }\end{array}$} \\
\hline & 0 & 1 & 2 & 3 & 4 & 0 & 1 & 2 & 3 & 4 \\
\hline $\begin{array}{l}\text { 1. Provide less than optimal care due to pressures to } \\
\text { reduce costs. }\end{array}$ & & & & & & & & & & \\
\hline $\begin{array}{l}\text { 2. Ask the patient's family about donating organs when } \\
\text { the patient's death is inevitable. }\end{array}$ & & & & & & & & & & \\
\hline $\begin{array}{l}\text { 3. Follow the family's wishes to continue life support } \\
\text { even though it is not in the best interest of the patient. }\end{array}$ & & & & & & & & & & \\
\hline $\begin{array}{l}\text { 4. Initiate extensive life-saving actions when I think it } \\
\text { only prolongs death. }\end{array}$ & & & & & & & & & & \\
\hline $\begin{array}{l}\text { 5. Follow that family's request not to discuss death with } \\
\text { dying patient who asks about dying. }\end{array}$ & & & & & & & & & & \\
\hline $\begin{array}{l}\text { 6. Carry out the physician's orders for what I consider to } \\
\text { be unnecessary tests and treatments for terminally ill } \\
\text { patients. }\end{array}$ & & & & & & & & & & \\
\hline $\begin{array}{l}\text { 7. Continue to participate in care for a hopelessly injurec } \\
\text { person who is being sustained on a ventilator, when no } \\
\text { one will make a decision to "pull the plug". }\end{array}$ & & & & & & & & & & \\
\hline $\begin{array}{l}\text { 8. Follow the physician's order not to tell the patient the } \\
\text { truth when he/she asks for it. }\end{array}$ & & & & & & & & & & \\
\hline $\begin{array}{l}\text { 9. Assist a physician who in my opinion is providing } \\
\text { incompetent care. }\end{array}$ & & & & & & & & & & \\
\hline $\begin{array}{l}\text { 10. Prepare an elderly person for surgery to have a } \\
\text { gastrostomy tube put in who is severely demented and a } \\
\text { "No Code". }\end{array}$ & & & & & & & & & & \\
\hline
\end{tabular}




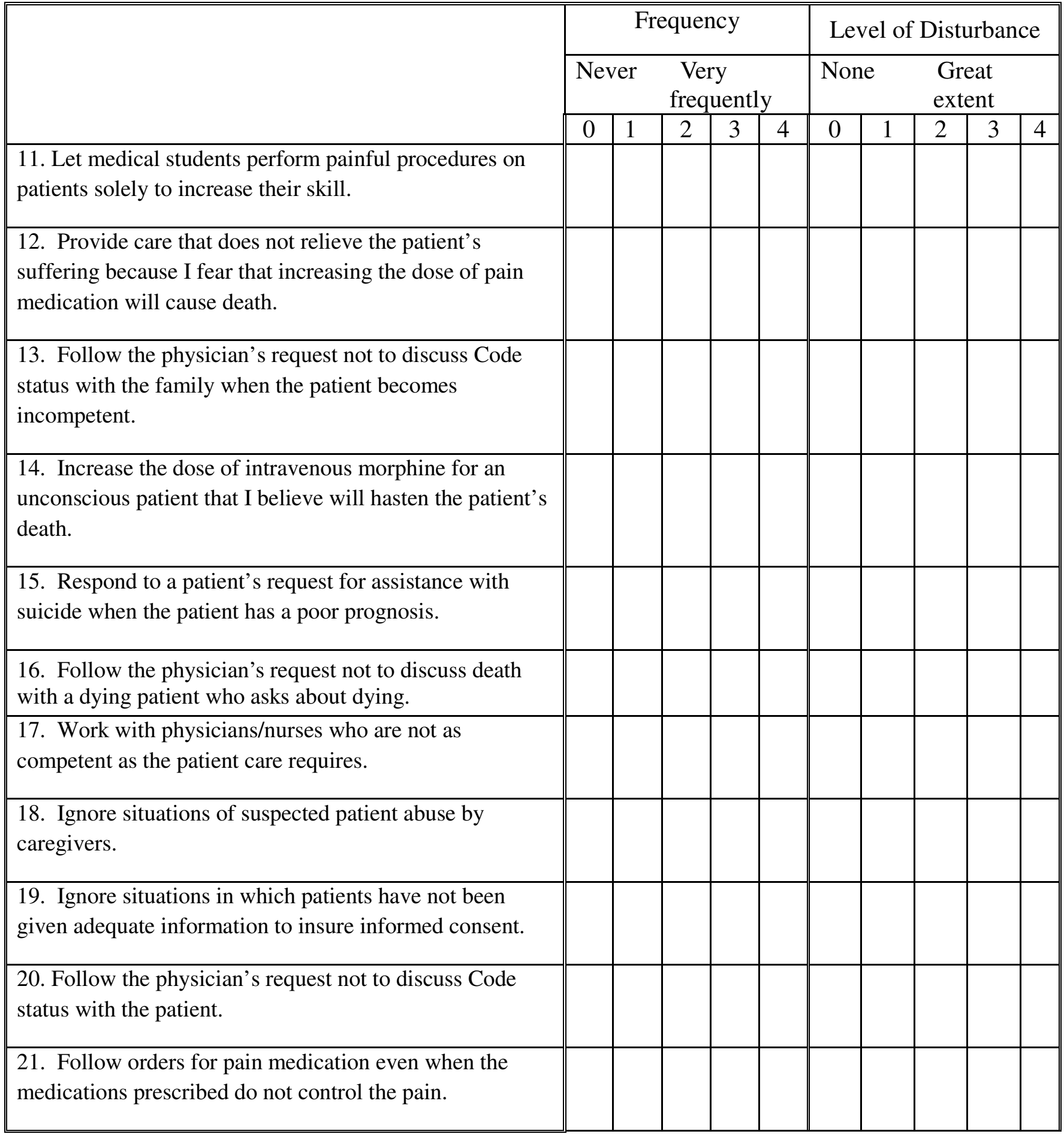




\section{MORAL DISTRESS}

Yes
I considered quitting but did not leave
No, I have never considered quitting nor left

Hamric, A. B., \& Blackhall, L. J. (2007). Nurse-physician perspectives on the care of dying patients intensive care units: Collaboration, moral distress, and ethical climate. Critical Care Medicine, 35, 422-429. 


\section{Appendix B}

Hospital Ethical Climate Survey

Directions: Below is a series of statements relating to various practices within your work setting. Please respond in terms of how it is in your current job on your current unit. As you read and respond to each statement, think of some difficult patient care issues you have faced. For those items that refer to your manager, think of your immediate manager (nurse manager, assistant nurse manager). It is important that you respond in terms of how it really is on your unit; not how you would prefer it to be. It is essential to answer every item. There are no right or wrong answers, so please respond honestly. Your responses are anonymous. Please read each statement and circle one number on each line to indicate your response.

\section{Almost}

Almost Seldom Sometimes Often

\section{Always True}

$\underline{\text { Never True }} \underline{\text { True }} \underline{\text { True }} \underline{\text { True }}$

1. My peers listen to my concerns about patient care. . $\quad \begin{array}{lllll}1 & 2 & 3 & 4 & 5\end{array}$

2. Patients know what to expect from their care . . . . . $1 \begin{array}{llllll} & 1 & 2 & 3 & 4 & 5\end{array}$

3. When I'm unable to decide what's right or wrong in

a patient care situation, my manager helps me. . . . . . 12

4. Hospital policies help me with difficult patient care issues $/$ problems . . . . . . . . . . . . 12

5. Nurses and physicians trust one another. . . . . . . 12

6. Nurses have access to the information necessary to solve a patient care issue/problem. . . . . . . . . 1

2

3

4

7. My manager supports me in my decisions about patient care . . . . . . . . . . . . . . . 1

8. A clear sense of the hospital's mission is shared with nurses 
MORAL DISTRESS

9. Physicians ask nurses for their opinions about

treatment decisions . . . . . . . . . . . . . . 1

3

4

5

10. My peers help me with difficult patient care issues/problems . . . . . . . . . . . . . . . 1

11. Nurses use the information necessary to solve a patient care issue/problem. . . . . . . . . . . . . . 12

12. My manager listens to me talk about patient care issues/problems. . . . . . . . . . . . . . . . 1

13. The feelings and values of all parties involved in a patient care issue/problem are taken into account when choosing a course of actions. . . . . . . . . 12

14. I participate in treatment decisions for my patients. . .1 2

$3 \quad 4 \quad 5$

15. My manager is someone I can trust. . . . . . . . . . . 12

16. Conflict is openly dealt with, not avoided. . . . . . . . 12

17. Nurses and physicians here respect each others' opinions, even when they disagree about what is best for patients. . . . . . . . . . . . . . 12

18. I work with competent colleagues. . . . . . . . . . . . 12

19. The patient's wishes are respected. . . . . . . . . . . . 12

20. When my peers are unable to decide what's right or wrong in a particular patient care situation, I have observed that my manager helps them. . . . . . . . .. 1

21. There is a sense of questioning, learning, and seeking creative responses to patient care problems. . . . . . 12

22. Nurses and physicians respect one another. . . . . . . 12

23. Safe patient care is given on my unit. . . . . . . . . . . 12

24. My manager is someone I respect. 
MORAL DISTRESS

should be practiced. . . . . . . . . . . . . . 12

3

4

5

26. Nurses are supported and respected in this hospital. . . 12 copyright Olson (1995) 


\section{Appendix C}

\section{Background Data}

Directions: Please circle the appropriate number OR fill in the blank. Responses are confidential.

\section{Gender}

Female ...............1

Male .................2

\section{What is your race?}

African-American................1

Caucasian........................2

Hispanic or Latino...............

Asian or Pacific Islander......4

American Indian..................5

Other (please specify) __ 6

\section{Age}

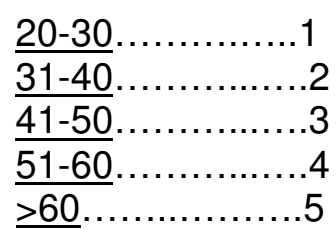

\section{What is your highest degree earned?}

Associate degree....................1

Diploma..............................2

Baccalaureate (Nursing)............3

Baccalaureate (Other field)...........4

Master's Nursing) .................... 5

Master's (Other field) ..............6

Doctoral Degree (Nursing)..........7

Doctoral Degree..................... 
5. How many years have you worked as a Registered Nurse?

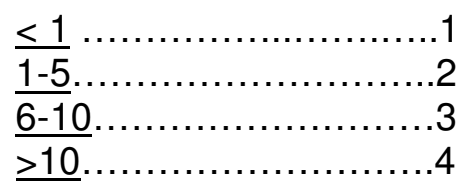

6. How many years have you worked as a

Registered nurse at this hospital?

$\leq 1 \ldots \ldots \ldots \ldots \ldots \ldots \ldots \ldots \ldots \ldots \ldots$

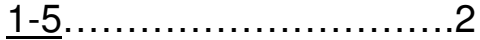

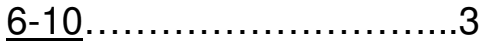

$\geq 10 \ldots \ldots \ldots \ldots \ldots \ldots \ldots \ldots . .4$

7. What is your present nursing position?

Staff nurse.............................

Manager........................................... 2

Other (specify) _ 3

8. How would you rate your overall job satisfaction?

Extremely satisfied ...............1

Very satisfied ..................... 2

Satisfied ........................... 3

Dissatisfied ........................4

Very dissatisfied ................... 5

Extremely dissatisfied .............6 


\section{References}

American Association of Critical Care Nurses (AACN). \{n.d. $\}$ The 4 A's to rise

above moral distress: Ask, affirm, assess, act. Retrieved December 17, 2012, from http://www.aacn.org/WD/Practice/Docs/4As to Rise Above Moral Distress.pdf

Begat, I., Ellefsen, B, \& Severinsson, E. (2005). Nurses' satisfaction with their work environment and the outcomes of clinical nursing supervision on nurses' experiences of well-being - a Norwegian study. Journal of Nursing Management, 13, $221-230$.

Bowles, C., \& Candela, L. (2005). First job experiences of recent RN graduates: Improving the work environment. Journal of Nursing Administration, 35(3), 130 - 137.

Buerhaus, P. I., Auerbach, D. I., \& Staiger, D. O. (2009). The recent surge in nurse employment: Causes and implications. Health Affairs, 28(4), 657 - 668.

Corley, M. C., Elswick, R. K., Gorman, M., \& Clor, T. (2001). Development and evaluation of a moral distress scale. Journal of Advanced Nursing. 33(2) 250-256.

Gallagher, A. (2011). Moral distress and moral courage in everyday nursing practice. Online Journal of Issues in Nursing, 16(2).

Haggstrom, E., Mbusa, E., \& Wadensten, B. (2008). Nurses' workplace distress and ethical dilemmas in Tanzanian health care. Nursing Ethics, 15(4), 478 - 491.

Hair, Jr., J. F., Black, W. C., Babin, B. J., Anderson, R. E., \& Tatham, R. L. (2006). Multivariate data analysis (6th ed.). Upper Saddle River, NJ: Pearson Education, Inc. 
MORAL DISTRESS

Hamric, A. B., \& Blackhall, L. J. (2007). Nurse-physician perspectives on the care of dying patients in intensive care units: Collaboration, moral distress, and ethical climate. Critical Care Medicine, 35(2), $422-429$.

Jameton, A. (1984). Nursing practice: The ethical issues. Englewood Cliffs, NJ: Prentice Hall.

Kupperschmidt, B., Kientz, E., Ward, J., \& Reinholz, B. (2010). A healthy work environment: It begins with you. OJIN: The Online Journal of Issues in Nursing, 15(1). doi:10.3912/OJIN.Vol15No01Man03

Murray, J. S. (2007). Creating ethical environments in nursing. American Nurse Today, 2(10), 4849.

Nielsen G.A., Bartely, A., Coleman, E., Rutherford, P. \& Taylor J. (2008). Transforming Care at the Bedside How-to Guide: Creating an Ideal Transition Home for Patients with Heart Failure. Cambridge, MA: Institute for Healthcare Improvement. Available at www.IHI.org.

Olson, L. L. (1998), Hospital nurses' perceptions of the ethical climate of their work setting. Journal of Nursing Scholarship, 30, 345-349. doi: 10.1111/j.1547-5069.1998.tb01331

Pendry, P. S. (2007). Moral distress: Recognizing it to retain nurses. Nursing Economics, 25(4), $217-221$.

Schluter, J., Winch, S., Holzhauser, K., \& Henderson, A. (2008). Nurses' moral sensitivity and hospital ethical climate: A literature review. Nursing Ethics, 15(3), 304-321.

Sherman, R., \& Pross, E. (January 31, 2010). Growing future nurse leaders to build and sustain healthy work environments at the unit level. The Online Journal of Issues in Nursing, DOI: 10.3912/OJIN.Vol15No01Man01.

Silen, M., Svantesson, M., Kjellstrom, S., Sidenvall, B., \& Chirstensson, L. (2011). Moral distress and ethical climate in a Swedish nursing context: Perceptions and instrument and usability. Journal of Clinical Nursing, 20, 3483-3493. 
MORAL DISTRESS

Storch, J., Rodney, P., Pauly, B., Brown, H. \& Starzomski, R. (2002). Listening to nurses' moral voices: Building a quality health care environment. Canadian Journal of Nursing Leadership, 15(4), 7 - 15.

Takase, M., Kershaw, E., \& Burt, L. (2001). Experience before and throughout the nursing career. Journal of Advanced Nursing, 35, 819-826.

Ulrich, C., O’Donnell, P., Taylor, C., Farrar, A., Danis, M., \& Grady, C. (2007). Ethical climate, ethics stress, and the job satisfaction of nurses and social workers in the United States. Social Science \& Medicine, 65(8), 1708-1719. 